\title{
Partial melting, granulites, retrogression and their control on late orogenic exhumation processes
}

\author{
BÉNÉDICTE CENKI-TOK ${ }^{1,2}$, PATRICE F. REY ${ }^{2}$, DiANE \\ ARCAY $^{1}$
}

${ }^{1}$ School of Geosciences, The University of Sydney, Sydney, Australia

${ }^{2}$ Géosciences Montpellier UMR5243, Université de Montpellier, CNRS, 34095 Montpellier cedex 5, France

Orogenesis drives the differentiation of the continental crust through metamorphic and magmatic processes, the exhumation of deep metamorphic terrains and the concomitant formation of sedimentary basins. A major consequence of prograde metamorphism following a typical orogenic thermal gradient is the dehydration and partial melting of buried rocks leading to the formation of migmatites and granulites. Partial melting and granulitisation are often intertwined and primarily linked to the availability of fluids. Here, we consider the thermal and mechanical consequences of coupled partial melting, granulitisation and strain-rate dependent retrogression during the orogenic cycle, in particular during the recovery phase when the crust thickness and geotherm re-equilibrate. We explore through 2D thermo-mechanical modelling how the interplay between mechanical weakening due to partial melting and mechanical strengthening due to granulitisation impacts the modes of deep crust exhumation, the formation of gneiss domes, the survival of granulitic terrains during exhumation and the partitioning of deformation through the crust.

Our results show that the survival of granulites, which strengthen the lower crust and decrease its capacity to flow under gravitational stresses, impedes the formation of migmatite-cored gneiss domes, and controls the formation and preservation of thick and strong granulitic roots. These are strong enough to stay immune to gravitational stresses and persist over hundreds of million years. These can be actually compared with stable intracontinental regions where the presence of localized crustal roots explains the remarkable variability - from 25 to $65 \mathrm{~km}$ - of crustal thickness. Finally, our experimental results explain as well why some ancient orogenic domains exposed at the Earth's surface dominantly granulitic terranes (e.g., Proterozoic orogens in South India, Sri Lanka, Madgascar, Antarctica, Baltica), whereas others (Variscides) expose dominantly migmatitic and granitic crust. 